\title{
Study on Technical Performance of Composite Modified Wide Temperature Field Asphalt Mixture
}

\author{
Jingxiang Yuan \\ Chongqing Radio \& TV University \\ No. 1, Hualong Avenue, Jiulongpo District, Chongqing China, 400052
}

\begin{abstract}
Because the Asphalt concrete pavement heavy-duty rutting, low temperature cracking and anti-fatigue cracking problems are prominent, the author mix the BRA rock asphalt and polyester fiber into the asphalt mixture preparation of wide temperature field asphalt mixture in accordance with various proportions. By making use of the comprehensive modification function of asphalt mixture, this thesis evaluates the road performance of the composite modified asphalt mixture. Test results: BRA and polyester fiber compound can greatly improve the integrated road performance of BRA rock asphalt and polyester fiber modified asphalt mixture. After the mixture of BRA and polyester modifier with dry process, the composite asphalt mixture have both high and low temperature performance, and the high temperature performance increased by $45 \%$, low temperature performance increase by $82 \%$ comparing with SBS modified asphalt mixture. The anti - fatigue performance under the compound modification scheme is better than that of SBS modified asphalt mixture. Engineering practice shows that the combination of asphalt and polyester fiber asphalt mixture can improve the comprehensive road performance of asphalt pavement, and it can replace SBS modified asphalt.
\end{abstract}

Keyword-road engineering; Burton rock asphalt; polyester fiber; compound modified asphalt mixture; road performance

\section{INTRODUCTION}

China has a vast and with different local temperatures. In the northern hemisphere, winter temperature is relatively low for a long time, while in summer, the temperature is relatively high with more rain. Especially in extreme weather, It is normal for the asphalt pavement to withstand $-40-70{ }^{\circ} \mathrm{C}$ temperature gap. As a result, it also caused Asphalt road rut disease, especially prominent problem is rutting cracking, affecting not only the road safety and road durability for vehicle driving, but also caused economic losses [1. 2]. The key to increase the load of asphalt pavement asphalt concrete of asphalt pavement road traffic is to effectively improve the integration program of the road structure to enhance the expectancy of the road. The study results at home and abroad show that the shear stress is the largest $5-7 \mathrm{~cm}$ beneath the the asphalt pavement structure road with the driving load of the vehicle, because the middle and lower layers of the pavement structure are the main positions of the asphalt pavement rutting. In this position, the use of anti-rutting agents, high modulus agent and rock asphalt effectively improves the resistance of the road to high temperature and deformation and its duration ability.
In order to improve the high temperature performance of asphalt pavement, in recent years, there is a wide use of natural asphalt in many of China 's newly-built asphalt road, road renovation project and prevention maintenance. Natural asphalt, modified asphalt and its mixture has always been the focus of road workers and researchers. Zeng Menglan and other researchers in Hunan University have made a research on the penetration performance indicators of European rock asphalt modifies asphalt. The results show that [3], adding rock asphalt can improve the high temperature performance, temperature sensitivity and anti-aging properties of asphalt, but will reduce the expansion of asphalt. Lu Zhaofeng in Chongqing Jiaotong University and other researchers studied the high and low temperature performance and water stability. The results show that [4] the high temperature performance and water stability of the asphalt mixture after adding Qingchuan rock asphalt are improved, while the low temperature decreased. Andit is recommended that the suitable Qingchuan rock asphalt content is 8\% (asphalt mixture mass percentage). Huang Wentong in South China University of Science and Technology studied the modification effect of North American rock asphalt on Aggregate Bit No. 7, The results show that [5], adding rock asphalt can improve the high temperature performance, stiffness modulus and fatigue resistance of asphalt, but the asphalt low temperature performance improvement is not obvious or there is an adverse effect. Guo Zhongyin in Tongji University studied the mix design and road performance of BRA modified asphalt mixture, the result show that [6], BRA rock asphalt can be used in high temperature area, but not in the low temperature area. Zhu Afeng in Chang'an University studied the road performance of the Bentonite asphalt modified asphalt mixture. The Result show that Bentonite asphalt could significantly improve the long-term performance and fatigue resistance of asphalt mixture [7]. Cao Dongwei in Ministry of Transportation studied the modification mechanism of natural asphalt on petroleum asphalt. The results show that the addition of natural asphalt remarkably improves the water stability of asphalt mixture [8]. Ni Fujian in southeast University and other researchers Trinidadu asphalt modified asphalt mixture of road performance, studies have shown that [9] Lake asphalt modified asphalt softening point high, anti-aging ability, can greatly improve the asphalt mixture rutting resistance Performance, while significantly improving the asphalt mixture resistance to water damage performance.

In order to improve the high temperature performance of asphalt pavement, in recent years, there is a wide use of 
natural asphalt in many of China's newly-built asphalt pavement, pavement renovation project and preventive maintenance. Natural asphalt modified asphalt and its mixture have always been the focus point of road workers and researchers.

At present, countries around the world make researches on rock asphalt and fiber modifier limited to a single modification, or use the composite fiber modification program [7-9]. However, we rarely see the research results on rock asphalt and polyester fiber composite modification. What' s more, they rarely use rock asphalt and polyester fiber complex in the roads with heavy load. In order to avid the situation of high temperature stability of the asphalt concrete overlay of the asphalt concrete and the low temperature crack resistance, we will again mix the BRA and the polyester fiber according to the same proportion. at the same time, we will also make wide temperature field asphalt mixture with asphalt mixture. we will use the different road performance polyester and BRA to give a full play of comprehensive role in the modification of asphalt mixture.

\section{StUdy ON RAW MATERIAL PROPERTIES}

The experimental study was conducted by using the Shell $70 \mathrm{~A}$ heavy traffic road petroleum asphalt in engineering practice, and use the I-CSBS modified asphalt(SBS content is 4. 5\%) in northern China as the experimental control group.

All the technical performance of asphalt were conform to " Highway asphalt pavement construction technical specifications "(JTG F40-2004) technical indicators requirements. Many research and construction practices tell us that polyester fiber can well adsorb the asphalt, reducing the leakage and pan oil phenomenon of asphalt pavement in high temperature; the function of fiber reinforcement and interface enhancement significantly improved the low temperature performance of asphalt mixture and Anti-fatigue durability. According to the different road performance, the fiber plays a different role in the asphalt mixture. Through the road performance and economic comparison, solid engineering used in polyester fiber, refer to "highway asphalt pavement construction technical specifications" (JTG F40 -2004) and " Asphalt pavement with polyester fiber national standard "(JT-T533 -2004) on the technical performance of polyester fiber were tested, the results shown in Table 1

TABLE I. LIGNIN FIBER TECHNOLOGY TESTING RESULTS

\begin{tabular}{|c|c|c|c|}
\hline Testing item & Length /mm & $\begin{array}{c}\text { Elongation } \\
\text { break } / \%\end{array}$ & $\begin{array}{c}\text { density /( g· cm }- \\
\text { 3) }\end{array}$ \\
\hline Testing results & $2 \sim 4$ & 34.7 & 1.38 \\
\hline $\begin{array}{c}\text { Technological } \\
\text { requirements }\end{array}$ & $\leq 6$ & $\geq 15$ & - \\
\hline $\begin{array}{c}\text { Oil absorption } \\
\text { rate( fiber quality } \\
\text { times) }\end{array}$ & $\begin{array}{c}\text { Tensile } \\
\text { strength } \\
/ \mathrm{MPa}\end{array}$ & diameter /mm & Water content rate $/ \%$ \\
\hline 4.38 & 550 & $<0.1$ & 1.4 \\
\hline$\geq 3$ & $\geq 350$ & $\leq 0.1$ & $\leq 3$ \\
\hline
\end{tabular}

TABLE II. BUTON ROCK ASPHALT TEST RESULTS

\begin{tabular}{|c|c|c|}
\hline Testing index & $\begin{array}{l}\text { Testing } \\
\text { result }\end{array}$ & Standard in Indonesia \\
\hline Asphalt content /\% & 25.3 & $\geq 18$ \\
\hline Ash content $/ \%$ & 74.8 & \\
\hline $\begin{array}{c}\text { density / ( } \mathrm{g} \cdot \mathrm{cm}- \\
3 \text { ) }\end{array}$ & 1.81 & $1.70 \sim 1.90$ \\
\hline Water content /\% & $<1$ & $\leq 2.0$ \\
\hline Flashing point / ${ }^{\circ} \mathrm{C}$ & $\geq 230$ & $\geq 230$ \\
\hline $\begin{array}{l}\text { Softening point of } \\
\text { asphalt recycle / }{ }^{\circ} \mathrm{C}\end{array}$ & 94.7 & $90 \sim 99$ \\
\hline
\end{tabular}

In another set of experiments, the BRA rock bitumen produced in Indonesia was used as raw material, and the test results of the Bentonite asphalt test performance are shown in Table 2. In the course of the research, we use basalt crushed stone as coarse aggregate and limestone sand as fine aggregate. All the aggregate indicators meet the regulatory requirements.

\section{MiXing Ratio Design of Asphalt MiXture IN WidE TEMPERATURE FIELD}

\section{A. Fiber and BRA Blending Ratio}

The content of fiber in SMA mixture in reference projects is $3 \%$ The content of polyester fibers in the experiment is $2 \%$, $3 \%$ and $4 \%$. The amount of fiber in the group was $4 \%, 6 \%$, $8 \%$ and $10 \%$ respectively. There are 4 kinds of BRA content, we use different road performance of BRA and polyester and their improvement focus to give a play to the comprehensive role in the modification.

\section{B. Determine the Mix Gradation and the Optimum Pitch Ratio}

The optimum pitch ratio of polyester fiber BRA modified asphalt mixture was determined according to the current specification JTG F40-2004 "Marshall method". In the experiment, the mixture of polyester fiber and Bentonite asphalt (BRA) was carried out by "dry" modification process. The addition and modification function of BRA to BRA mixture are mainly happened in the process of the mixing process. The heating temperature of the aggregate, the mixing temperature and time of the mixture play a decisive role in the modification of the rock asphalt $[10,11]$. The heating temperature of the aggregate is $195-200{ }^{\circ} \mathrm{C}$, the dry mixing time of the BRA and the aggregate id 90s. we first let the BRA fully melt and spread in the minerals, and then observe its distribution. There is no obvious sticking, and then add matrix asphalt until it is evenly dispersed , mixing for 60s. Finally adding slag and mixing for $60 \mathrm{~s}$, the total mixing time is 3.5 min. The temperature control of the "dry" process during the test is shown in Table 3, 
TABLE III. POLYESTER FIBER /BRA MODIFIED ASPHALT MIXTURE MARSHALL TEST TEMPERATURE CONTRO

\begin{tabular}{|c|c|}
\hline Testing process & Control standard $/{ }^{\circ} \mathrm{C}$ \\
\hline Aggregate heating temperature & $190 \sim 200$ \\
\hline $\begin{array}{c}\text { Matrix asphalt heating point } \\
\text { Asphalt mixture mixing } \\
\text { temperature }\end{array}$ & $155 \sim 160$ \\
\hline $\begin{array}{c}\text { Specimen compaction } \\
\text { temperature }\end{array}$ & 165 \\
\hline
\end{tabular}

\section{PAVEMENT PERFORMANCE OF POLYESTER FIBER / BRA ROCK ASPHALT COMPOSITE MODIFIED ASPHALT MIXTURE}

\section{A. High Temperature Stability Test}

The high temperature stability of BRA and polyester fiber composite modified asphalt mixture was evaluated by rutting test. Because in summer, the temperature is so high so we make the research by adding $70{ }^{\circ} \mathrm{C}$ to check its rutting. Rutting test specimen preparation and test loading method are in strict accordance with the requirements of JTGE20-2011 implementation, the wheel pressure is $0.7 \pm 0.05 \mathrm{MPa}$, walking speed is $42 \pm 1$ times / min, the wheel walking direction should be in accordance with the rutting direction of the rutting board when the rolling is normal. The rut test results are shown in Table 4.

In addition, under the same BRA content, the dynamic stability of the composite modified asphalt mixture rutting increases linearly with the increase of the polyester fiber content, but the improvement to the dynamic stability of polyester fiber to the compound modified asphalt mixture rutting test is not as obvious as BRA. (2)when the content of polyester fiber is $3 \%$, the adding of $6 \%$ BRA in the modified asphalt mixture can increase the DS of composite modified asphalt mixture by 35 . 8\%, while $10 \%$ BRA content can increase the DS by $106.5 \%$. BRA significantly improved the resistance against high temperature and deformation of composite modified asphalt mixture. with DS more than 3000 times / $\mathrm{mm}$ as the control index to ensure that the composite modified asphalt mixture has sufficient anti-permanent deformation ability, the content of BRA should not be less than 6\%; (3) With the same content of BRA, the dynamic stability of the rutting test increases linearly with the increase of the amount of polyester fiber, and the growth rate of the rutting test dynamic stability is very even when the content polyester fiber is more than $3 \%$. Comparing with ordinary asphalt mixture, Though the addition of polyester fiber has a certain effect on the dynamic stability of the composite modified asphalt mixture rutting test, its effect on the high temperature performance of the mixture is limited. (4)By using the compound modification scheme, the dynamic stability of rutting test of the asphalt mixture can be stabilized to over 3000 times $/ \mathrm{mm}$. The results of the rutting test under the 10\% BRA and $3 \%$ polyester compound modification scheme are comparable to those of the $4 \%$ SBS modified asphalt mixture. After the addition of BRA rock asphalt, the mixture Dynamic stability has been greatly improved. These data fully illustrate the BRA additive can improve the anti-permanent deformation of asphalt mixture, so that the high temperature stability can be improved.

\section{TABLE IV. TABLE IV. RUTTING TEST RESULTS}

\begin{tabular}{|c|c|c|c|c|}
\hline \multirow{2}{*}{$\begin{array}{l}\text { Polyester/ } \\
\% \text { \% }\end{array}$} & \multirow{2}{*}{$\begin{array}{c}\text { BRA } \\
\text { contents/ } \\
\%\end{array}$} & \multicolumn{2}{|c|}{$\begin{array}{c}\text { Dynamic stability of rutting } \\
\text { test } /(\mathrm{mm}-1)\end{array}$} & \multirow{2}{*}{$\begin{array}{c}\text { Decreasin } \\
\text { g rate } / \%\end{array}$} \\
\hline & & $60{ }^{\circ} \mathrm{C}$ & $70{ }^{\circ} \mathrm{C}$ & \\
\hline 0 & 0 & 1844 & 632 & 65.7 \\
\hline 3 & 0 & 2084 & 1009 & 44. 6 \\
\hline 0 & 8 & 3762 & 2467 & 34.4 \\
\hline \multirow{4}{*}{2} & 4 & 2989 & 1717 & 42.5 \\
\hline & 6 & 3592 & 2812 & 34.5 \\
\hline & 8 & 4456 & 2920 & 34.5 \\
\hline & 10 & 4929 & 3097 & 34.5 \\
\hline \multirow{4}{*}{3} & 4 & 3184 & 1976 & 37.9 \\
\hline & 6 & 4194 & 3621 & 30.3 \\
\hline & 8 & 5319 & 3712 & 30.2 \\
\hline & 10 & 5471 & 3817 & 30.2 \\
\hline \multirow{4}{*}{4} & 4 & 3587 & 2905 & 46. 8 \\
\hline & 6 & 5618 & 4026 & 28.3 \\
\hline & 8 & 5761 & 4119 & 28.5 \\
\hline & 10 & 5900 & 4209 & 28.7 \\
\hline \multicolumn{2}{|c|}{ SBS } & 4896 & 2250 & 39.7 \\
\hline
\end{tabular}

\section{B. Low Temperature Crack Resistance}

The low temperature crack resistance of BRA rock asphalt / polyester fiber composite modified asphalt mixture was studied by using the low-temperature bending test of trabecular beam. The damage strength, failure strain and failure modulus of the mixture were measured, and the unit volume of Low temperature destruction energy. Test method is in strict accordance with JTG E20-2011, the test results are shown in Table 5. 
TABLE V. LOW TEMPERATURE BENDING TEST RESULTS

\begin{tabular}{|c|c|c|c|c|c|}
\hline polyester/\%o & BRA content $/ \%$ & Anti-bending strength/MPa & Maximum bending strain $/ \mu \varepsilon$ & $\begin{array}{l}\text { Bending stiffness } \\
\text { modulus/MPa }\end{array}$ & $\begin{array}{c}\text { Unit damage strain } \\
\text { energy/( } \mathrm{kJ} \cdot \mathrm{m} \text { - } \\
3 \text { ) }\end{array}$ \\
\hline 3 & 10.43 & 2763.73 & 2763.73 & 24. 92 & 24.43 \\
\hline 0 & 10.35 & 2457.56 & 2457.39 & 22.90 & 22.45 \\
\hline \multirow{4}{*}{2} & 10.99 & 2778.74 & 4032.45 & 25.96 & 25.45 \\
\hline & 11.57 & 2900.61 & 4067.46 & 28.23 & 27.68 \\
\hline & 11.84 & 2908.60 & 4152.87 & 28.70 & 28.14 \\
\hline & 10.54 & 2798.12 & 3840.92 & 26.99 & 26.46 \\
\hline \multirow{4}{*}{3} & 11.39 & 3391.06 & 3427.03 & 31.76 & 31.14 \\
\hline & 12.27 & 3506.99 & 3568.87 & 32.99 & 32.34 \\
\hline & 12.36 & 3583.72 & 3518.59 & 33.81 & 33.15 \\
\hline & 11.24 & 3475.30 & 3299.06 & 32.61 & 31.97 \\
\hline \multirow{4}{*}{4} & 4 & 11.61 & 3443.73 & 3186.30 & 32.41 \\
\hline & 6 & 11.97 & 3512.42 & 3224.31 & 33.23 \\
\hline & 8 & 12.32 & 3653.68 & 3282.11 & 34.42 \\
\hline & 10 & 11.23 & $3456 . \quad 25$ & 3157.82 & 32.14 \\
\hline \multicolumn{2}{|c|}{ Matrix asphalt mixture } & 9. 30 & $2344 . \quad 19$ & 4047.64 & 21.40 \\
\hline \multicolumn{2}{|c|}{$\begin{array}{l}\text { 4\%SBS modified asphalt mixture } \\
\text { mixture } \\
\end{array}$} & 12.06 & 3435.87 & 3504.44 & 32.30 \\
\hline
\end{tabular}

TABLE VI. WATER STABILITY TEST RESULTS

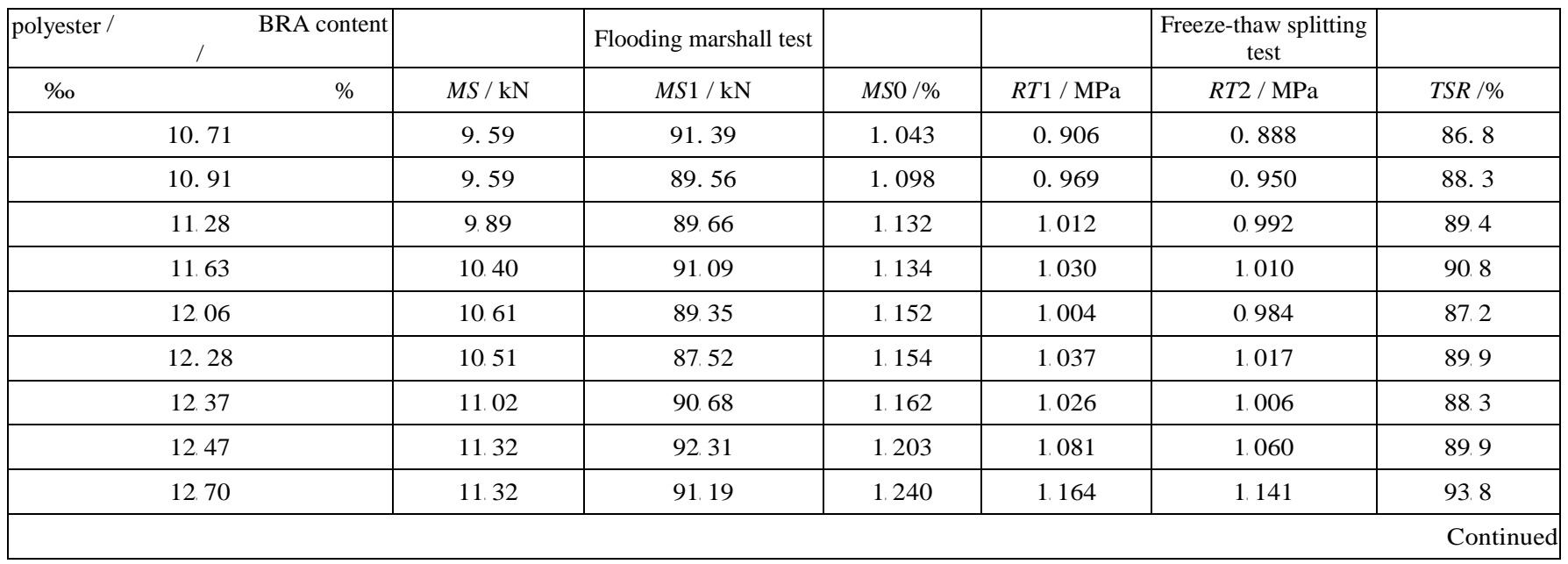

TABLE VII. WATER STABILITY TEST RESULTS

\begin{tabular}{|c|c|c|c|c|c|c|}
\hline polyester/ & & Flooding marshall test & & & $\begin{array}{c}\text { Freeze-thaw splitting } \\
\text { test }\end{array}$ \\
\hline \%o content / & & & & RT2 / MPa & TSR /\% \\
\hline 12.92 & $M S / \mathrm{kN}$ & $M S 1 / \mathrm{kN}$ & $M S 0 / \%$ & $R T 1 / \mathrm{MPa}$ & 1.203 & 95.2 \\
\hline 12.76 & 11.42 & 90.27 & 1.289 & 1.227 & 1.187 & 92.8 \\
\hline 12.54 & 11.53 & 92.51 & 1.305 & 1.211 & 1.127 & 87.3 \\
\hline 12.71 & 11.73 & 95.17 & 1.317 & 1.150 & 1.183 & 90.4 \\
\hline 12.94 & 12.04 & 96.29 & 1.335 & 1.207 & 1.228 & 93.7 \\
\hline Matrix asphalt mixtu & 12.44 & 98.23 & 1.337 & 1.253 & 0.801 & 80.3 \\
\hline 4\% SBS modified & 9.89 & 7.96 & 82.8 & 0.998 & 1.114 & 90.9 \\
\hline
\end{tabular}


The low temperature bending test result show that:(1)with the same content of BRA, as the content of polyester fiber increases, the resistance of the compound modified asphalt mixture to bending strength increases as well. Under the BRA content, the flexural strain increases linearly with the increase of the polyester content, and there is a similar trend to the per unit volume destruction energy. It can be seen that increasing the polyester content can improve the flexibility of the compound modified asphalt mixture. The maximum bending strain of the composite modified asphalt mixture is more than $3300 \mu \varepsilon$, that is, the low temperature crack resistance of the composite modified asphalt mixture is more sensitive to the polyester fiber; (2)With the same polyester content, as the BRA content increases, the flexural strain of composite modified asphalt mixture increased first and then decreased, showing that low temperature crack resistance is the main factor restricting the increase of BRA content; (3)Comparing with the SBS modified asphalt mixture, using BRA and polyester fiber composite modification program can be more effective than SBS modified asphalt mixture, improving the flexibility of the mixture.

\section{Water Stability}

The effects of polyester and BRA content on the water stability of the modified modified asphalt mixture were discussed by using immersion Marshall and freeze-thaw splitting test. The test method was strictly referred to the "Test Code for Asphalt and Asphalt Mixture" (JTG E20-2011), The test results are shown in Table 6.

The results show that the modified Marshall residual strength ratio and the freeze - thaw splitting strength of all the modified asphalt mixtures of BRA / polyester fiber compound scheme can reach more than $85 \%$ and meet the requirements of the specification. BRA / polyester fiber compound program modified asphalt mixture has excellent resistance to water damage, which is consistent with the existing research results. The reason is that the mineral powder contained in BRA rock asphalt has many years of natural asphalt infiltration and has strong surface activity, exhibiting strong hydrophobicity and lipophilicity. It can effectively improve the adhesion between asphalt and aggregate so as to improve the anti-water damage ability of the asphalt mixture. In addition, the fiber adsorption stability and interface enhancement can improve the adhesion between the asphalt mortar and aggregate.

\section{Anti-fatigue Durability}

Experiments and practices have proved that the fatigue properties of the modified asphalt mixtures with BRA are obviously increased compared with the matrix asphalt mixture, and the fatigue life at the same strain level is increased by at least $150 \%$. BRA / polyester fiber composite modified asphalt mixture is better than single fiber, BRA modified asphalt and SBS modified asphalt mixture, and BRA / polyester fiber composite modified asphalt mixture is less sensitive to the change of strain level. Considering the variation regularity of $\mathrm{k}$ and $\mathrm{n}$, the anti-fatigue performance of $4 \%$ polyester $+8 \%$ BRA, $3 \%$ polyester $+8 \%$ BRA, $3 \%$ polyester $+10 \%$ BRA are better than SBS modified asphalt mixture. The polyester fiber and BRA compound modifier can be used as an additive to enhance the fatigue properties of asphalt mixture.

\section{CONCLUSION}

The study of the effects of BRA and polyester fiber on the road performance of heavy duty asphalt mixture, the indoor test and engineering practice show that under the same content of polyester fiber, the dynamic stability of rutting test quadratics with the increase of BRA content. The modified program with polyester fiber and BRA can greatly improve the high temperature performance of asphalt mixture. The rutting test results show that the $10 \%$ BRA $+3 \%$ polyester fiber compound modification scheme are better than $4 \%$ SBS modified asphalt mixture. With the same BRA content, as polyester fiber content increased, anti-bending strength of composite modified asphalt mixture also increased. The use of polyester and BRA compound solution can significantly improve the anti-fatigue durability of asphalt mixture, which is better than SBS modified asphalt mixture.

\section{REFERENCES}

[1] Xiao Guiqing, Dong Zejiao, Analysis of rutting resistance of heavy duty asphalt pavement structure[J]. Highway Engineering, 2015, 40( 2) : 79-83.

[2] Wang Gang, Liu LIping. Experimental Study on Performance of Domestic Natural Rock Asphalt and Its Mixture[J]. Highway Engineering, 2014, 39(4) : 72-75.

[3] Zeng Menglan, Zhao Yu, Pan Haozhi, etc.Experimental Study on Performance of European Rock Asphalt Modified Asphalt Binder[J]. Journal of Hu Nan University: Natural Science Edition. 2016, 43( 5) : 125-130.

[4] Lu Zhaofeng, He Zhaoyi, Qing Hao. The use of natural asphalt modified asphalt mixture road performance[J]. Journal of Central South University:Natural Science Edition. 2016, 41 ( 6) : 2407-2411

[5] Huang Wentong, Guan Zuhua, Wu Chuanhai, etc. Study on the modification effect of North American rock asphalt on matrix asphalt[J]. Science technology and Engineering. 2014, 15(15) : 270-274.

[6] Liu Shutang, Budun rock asphalt modified design theory with asphalt and asphalt mixture[D]. Shang Hai: Tong Ji University, . 2009.

[7] Zhu afeng, Asphalt mixture Jiabudun rock asphalt performance research[D]. Xi'an: Chang An University, 2014.

[8] Cao Dongwei, Study on the mechanism of natural asphalt to improve road petroleum asphalt[J]. Petroleum asphalt, 2008, 22( 4) : 30-34.

[9] Ni Fujian, Lai Yongman, Shen Heng, etc.Study on pavement performance of TLA composite modified asphalt mixture [J]. Highway transportation technology, 2005, 22(1) , 13-16.

[10] Liu Shutang, Yang Yongshun. Experimental study of modified asphalt mixture of Buton rock asphalt [J].Journal of Tongji University, Natural Science Edition, 2007, 35( 3) : 351-355.

[11] Wang Hengbin, Ge Zhesheng. Experimental study on dynamic rheological properties of asphalt mortar modified by Buton rock asphalt[J]. Highway transportation technology, 2008, 25( 9) : 63-66. 